\title{
Good Professor Edmondson
}

Encounters with W. T. Edmondson in his laboratory-office are much the same for new graduate students, postdoctorals, or other professional colleagues. "Excuse me, Dr. Edmondson." A face looks up from the jigsaw puzzle of manuscript pages, letters, and "study graphs" (his term for meters-long plots of limnological data) which blankets his desk. A smile of greeting and invitation to sit, but first a stack of folders and reprints must be cleared from the nearby chair. The interrupted work seems as if forgotten, and Edmondson sits, delighted by the visit, and attentive to each word (Fig. 1).

Every student and visitor to his laboratory recalls the hastily cleared chair most of all, mindful that some thoughts had surely been displaced by the intrusion, but that such pure sign of welcome showed that all was well. So did the feeling of genuine interest which greeted each arrival, and the sense of quick curiosity about new developments, no matter what their source or dimension. Some of us undoubtedly concluded that this is evidence of a scholar's interest in all things, but another truth may be that this eminent ecologist is a genuinely warm and friendly individual (see photo collection, p. 1239-1240).

It is science, however, that draws colleagues to the lab in Seattle. Plankton ecologists, paleolimnologists, and students of lake trophic condition arrive to sample the intellectual atmosphere and discover a very pleasant laboratory environment from which to work. They encounter a mentor or coworker who has maintained a youthful enthusiasm for discovery and learning, so much so that in 1983 he suspended his own seminar course so that he could serve as teaching assistant for David Frey, when the latter offered a course in Quaternary studies as Visiting Professor. Not often do students have as TA a member of the National Academy of Sciences.

He was born in Milwaukee and raised through his very early years near the shores of Lake Michigan, so there may be truth in the notion that lakes imprinted strongly on him. His early publication record, however, makes it clear that he was drawn to lakes through the study of their organisms, particularly the Rotifera (Fig. 2). Receiving the B.S. from Yale in 1938 (Fig. 3), Edmondson managed to print eight scientific papers as an undergraduate, including one in Science. His work involved systematics, fixation methods, and substrate effects. It had begun, in fact, while he was still in Hillhouse (New Haven) high school. Urban schools were crowded even then, and New Haven had adopted a program of "split-sessions," by which students were educated in shifts, either in the morning or the afternoon. Far from seeing this as a failing for public education, Edmondson found the freedom to pursue his interests in the Osborn Memorial Laboratories of Yale.

Edmondson remained at Yale for his doctorate (1942), but in 1938-1939 he sojourned in the Midwest for professional interests, and coincidentally advanced some personal interests as well. He undertook studies at the University of Wisconsin and Trout Lake under Chancey Juday, investigating the chemical ecology of rotifers and separating various kinds of correlated effects of $\mathrm{pH}$, alkalinity, and ionic strength. While there he met Yvette Hardman (Fig. 4). Hardman was intrigued with the young man who kept shuttling during exams for more "blue-books" in which to write voluminous essay answers to questions about lakes. They were subsequently married in Dwight Chapel, New Haven, to the strains of Bach, performed by the university organist. That was in September 1941, hours after Edmondson had finished his preliminary exams for the Ph.D.

War intruded into academe, and for a while Edmondson became an oceanographer, working as a civilian for the U.S. Navy. By virtue of having passed a college course in advanced differential equations, Edmondson was declared a physical oceanographer and given various tasks during the war. First at the American Museum of Natural History and then at Woods Hole Oceanographic Institution, he was involved in wave-height predictions for such practical purposes as amphibious landings and proper placement of mines in harbors. At WHOI, Edmondson joined Walter Munk and Henry Stommel, who 


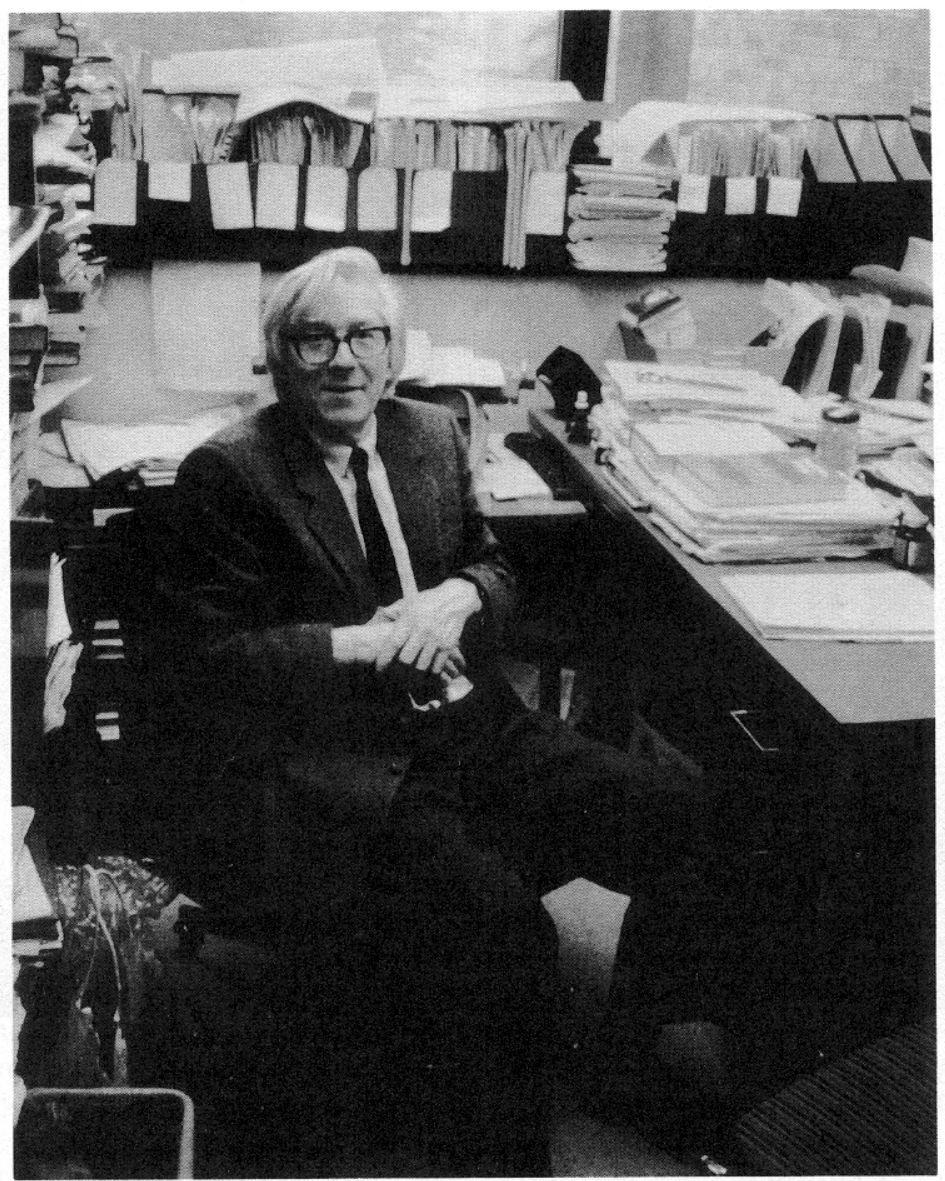

Fig. 1. W. T. Edmondson in his office in Kincaid Hall, University of Washington. Hastily cleared chair at lower right. (Photo by A. Litt.)

had developed a new theory for wave predictions. George Clarke led the scientific crew, and Edmondson was given the dubious honor of making measurements to discover whether real waves conformed to theory. His contributions involved expeditions in the worst possible weather, to measure conditions for which data were not otherwise available. During this time, Yvette was teaching at Bennington College, her alma mater, and the young couple shared only intermittent visits.

Later, and after other projects, Edmondson was assigned to a program whose goal was to help locate aircraft lost at sea. Edmondson worked for Maurice Ewing, studying sound refraction in the deep ocean as part of the pioneering studies of the SOFAR zone. In practice this meant deploying lots of depth charges at sea by hand. The seafaring work may have dampened the native imprint of Lake Michigan, because he never subsequently felt called to work with any great lake ecosystems. In fact, he quotes earnestly a statement by Gordon Riley to the effect that "Great Lakes research has all the disadvantages of oceanography and none of the advantages."

After the war he stayed on for a while at WHOI and as a lecturer at Harvard. The controls and measurement of biological productivity started to compete with his love for rotifers, and both he and Yvette investigated the relationships between nutrient content and the productivity of seawater. The idea of measuring biological productivity as an 


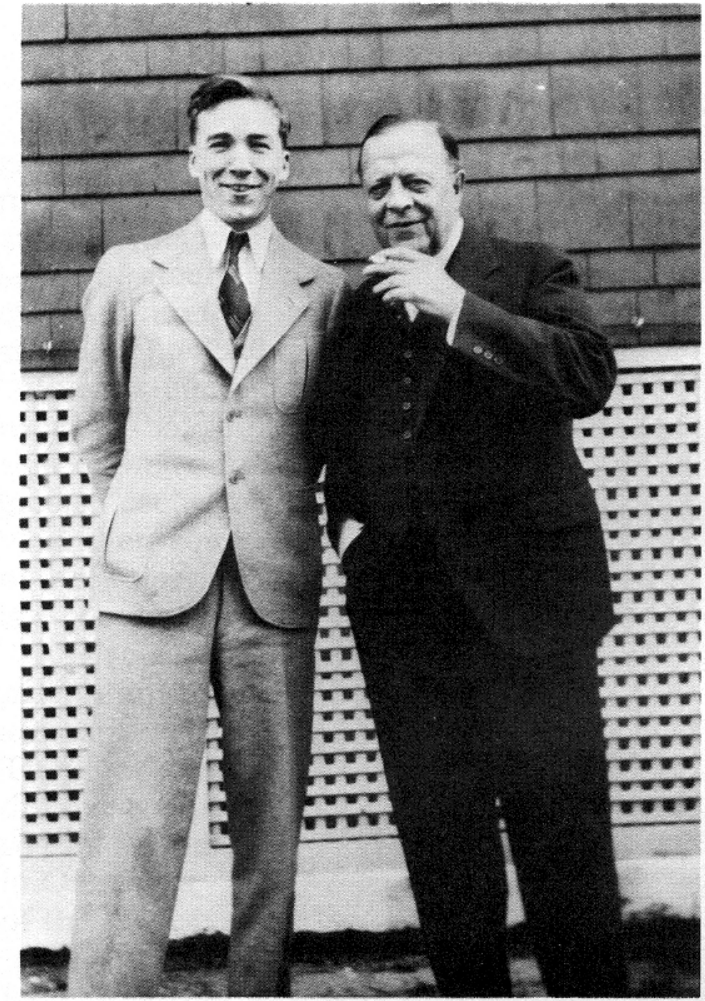

Fig. 2. With F. J. Myers during 1937 rotifer symposium. (Courtesy W. Koste.)

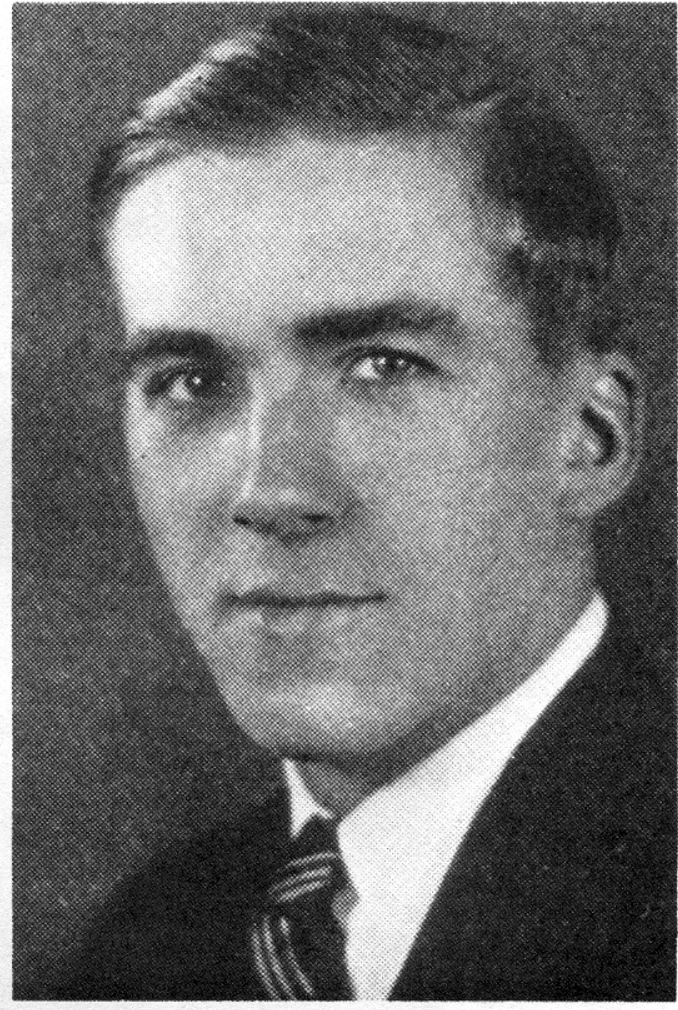

Fig. 3. Yale College, Sheffield Scientific School, Class of ' 38 .

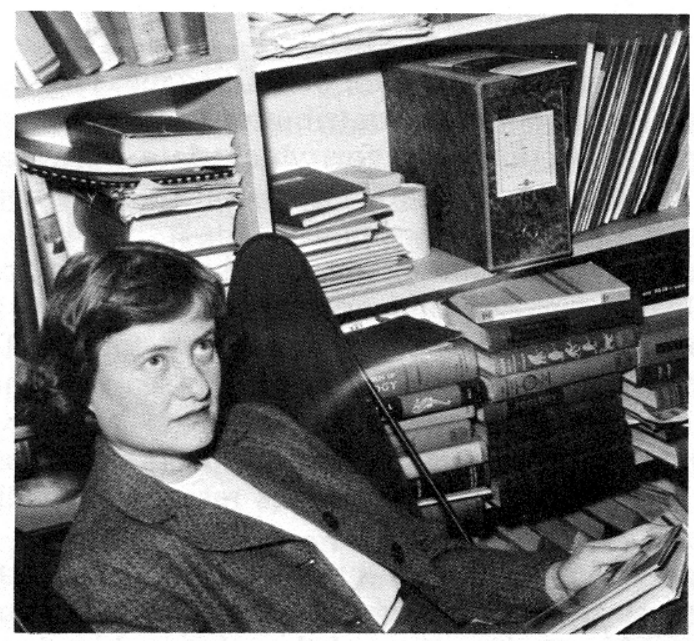

Fig. 4. Yvette Hardman Edmondson, ca. 1955. (Photo by J. O. Sneddon.) 
aggregate property of aquatic ecosystems was fostered by the growing interests of oceanographers, and embracing it must have opened new thoughts for one who had spent years studying the ecology of relatively cryptic organisms. The reconciliation of these interests, however, led to one of the most remarkable and widely used developments in quantitative plankton ecology.

Edmondson once remarked that he thought a scientist should be pleased if he had at least one good idea in his professional life. For some, the ideas are matters of personal insight and fulfillment which are not properly shared by a wide audience. In some cases, however, the ideas catch fire because they make what once seemed an intractable problem suddenly feasible. That is surely the case with the idea that the ratios between eggs and females in plankton collections could be converted into quantitative estimates of birth rates. Known to limnologists as Edmondson's egg ratio method, that single idea offered zooplankton ecologists the means to measure rates of population renewal by direct observation. Zooplankton biologists suddenly had a tool of inquiry which was comparable to the ${ }^{14} \mathrm{C}$ method for measuring the rates of renewal of algal populations, but which could be applied to individual species.

In the years after 1960, when the egg ratio method was introduced, zooplankton ecology entered a period of spectacular growth and discovery. The factors regulating community structure and species composition became understood as never before. The modern paradigms of zooplankton ecology started to emerge with the recognition that predation by fish and invertebrates was a central force. Insights to ecological and evolutionary processes surfaced, although in few cases was it possible to measure rates of predation directly. Rather, investigators relied on the fact that changes in populations within enclosed lake basins must be owed to the inequalities between birth and death rates. Edmondson's method permitted an estimate of birth, and death could be figured by difference.

Edmondson had moved to the University of Washington in 1949. There he began a pattern of limnological investigation that was to be the hallmark of his career for the next 40 years. Edmondson learned as a student that much could be discovered by focusing attention on lakes that were atypical in one characteristic or another. Within his first years at Seattle, Edmondson and his students selected several lakes, each of which expressed an exaggerated feature. Soap Lake and Lake Lenore on the Columbia Plateau of eastern Washington were saline, and they contained specialized biota. Hall Lake, a coastal kettle, was an example of biogenic meromixis. Lake Washington attracted no attention from Edmondson at first, although his students George Anderson and Gabe Comita undertook studies of the plankton. The lake simply had no unusual features.

Edmondson's interest awoke, however, in 1955 when Anderson discovered a novel development in Lake Washington: a new species of algae had become established in the lake. The discovery prompted Edmondson to study Lake Washington in earnest-a study which has arguably become the greatest single case study of eutrophication and recovery yet conducted. Edmondson started this work because the appearance of Oscillatoria rubescens signaled that Lake Washington was starting to follow a path of deterioration of water quality the likes of which had been seen previously in Europe and eastern North America. Here was a lake ecosystem responding to nutrient income the way that Woods Hole seawater responded to fertilization. Again, the study of productivity and lake organisms could be linked (Fig. 5). The long-term ecological investigation which resulted has become so thoroughly a part of limnological tradition that the responsiveness of lakes to nutrients is accepted as axiom. As R. T. Oglesby has put it, "The 'Lake Washington Story' has become to the limnologist what the Lord's Prayer is to a preacher, a vital, uniquely clear, well-documented statement of what the profession is all about."

At a time when U.S. science seeks teams of scientific specialists to tackle "multidisciplinary" challenges, it is well to recognize that special individuals have long faced the same challenges, but their response was to develop the personal breadth of understanding necessary for progress. Edmondson exemplifies the dedicated idealist who instinctively 


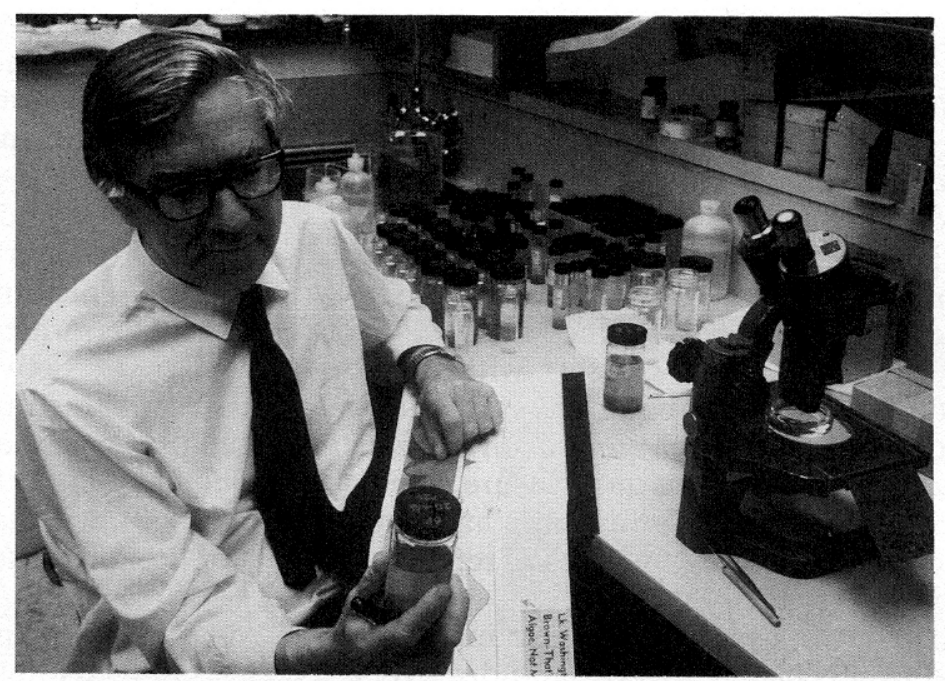

Fig. 5. Sorting Lake Washington plankton samples, ca. 1971.

has shunned the bureaucratic trappings of "big science," because they could not help him in his personal pursuit of truth about nature. As scholar and teacher he shows by example a unique blend of excellent science and humane concern for the quality of the environment. Few scientists are honored, as was he, by a special resolution of his State Legislature on the occasion of his academic retirement or by such a plethora of awards from universities, public service organizations, and professional societies. The tributes are heartfelt, in large measure because he has taught environmental science to scientist and nonscientist alike.

It is a high privilege to dedicate this issue of Limnology and Oceanography to W. T. Edmondson, Charter Member of ASLO and Past President, ESA Eminent Ecologist, and recipient of the Frederick Garner Cottrell Award for Environmental Quality of the National Academy of Sciences and the SIL Einar Naumann-August Thienemann Medal, with sincere wishes for continuing scholarly productivity. But first, a musical number (to the tune of "Good King Wenceslaus"):

Good Professor Edmondson walked outside one nooning, Looked out on Lake Washington, noticed it was blooming.

All the other scientists asked what was polluting.

Some said it was $\mathrm{CO}_{2}$; he said it was soo-oo-age.

The lake had turned a muddy brown from Oscillatoria.

Reminded of Lake Zurich, then, he was in euphoria.

All of the Seattleites looked on with aversion.

They believed their lake was dead; he called for diver-er-sion.

Voters took a public stand to make their lake look pretty.

Their task began in '63; it ended with Lake City.

They harkened to his learned words; pollution dropped to zero.

Good Professor Edmondson had become a he-ee-ro.

John T. Lehman

Department of Biology

Natural Science Building

University of Michigan

Ann Arbor 48109 


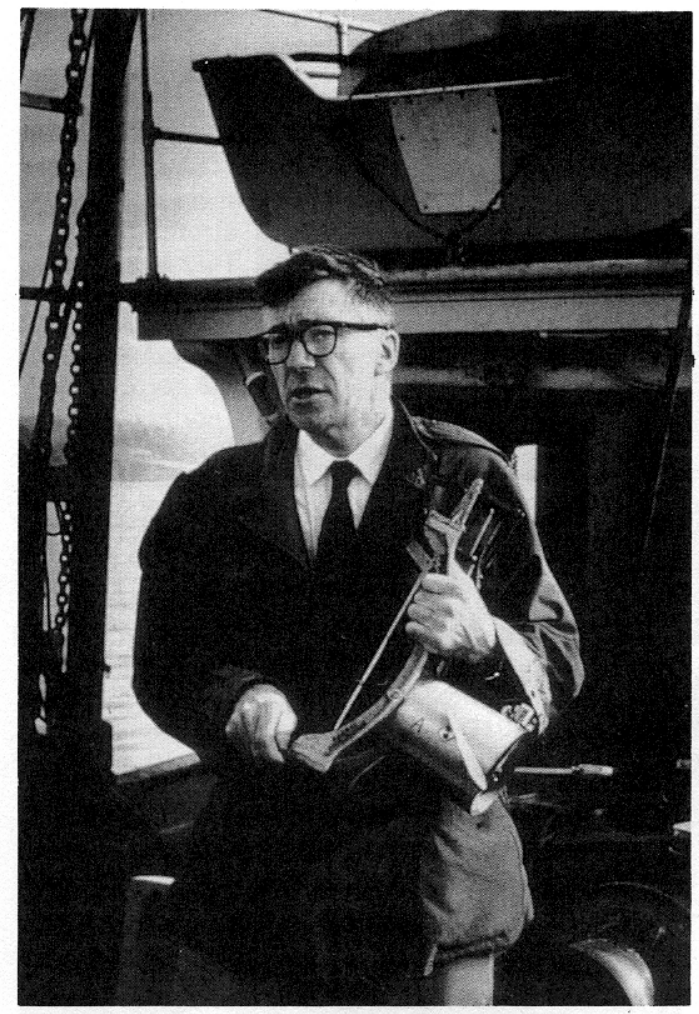

Limnology class trip on Lake Washington, October 1966.

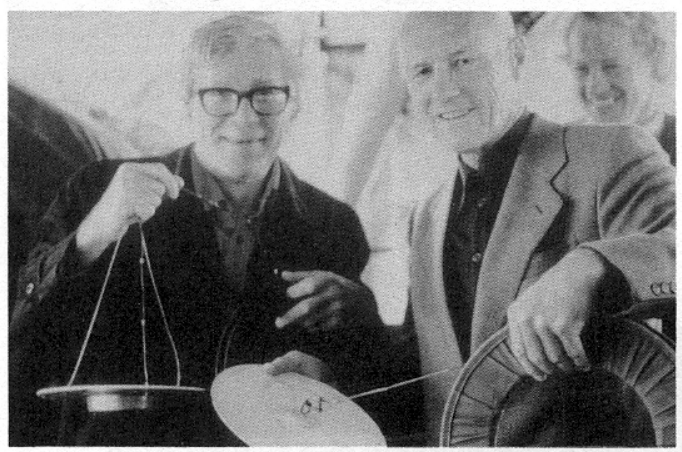

With A. Wuhrmann, preparing to collect wager over Secchi disk transparencies, 1971.

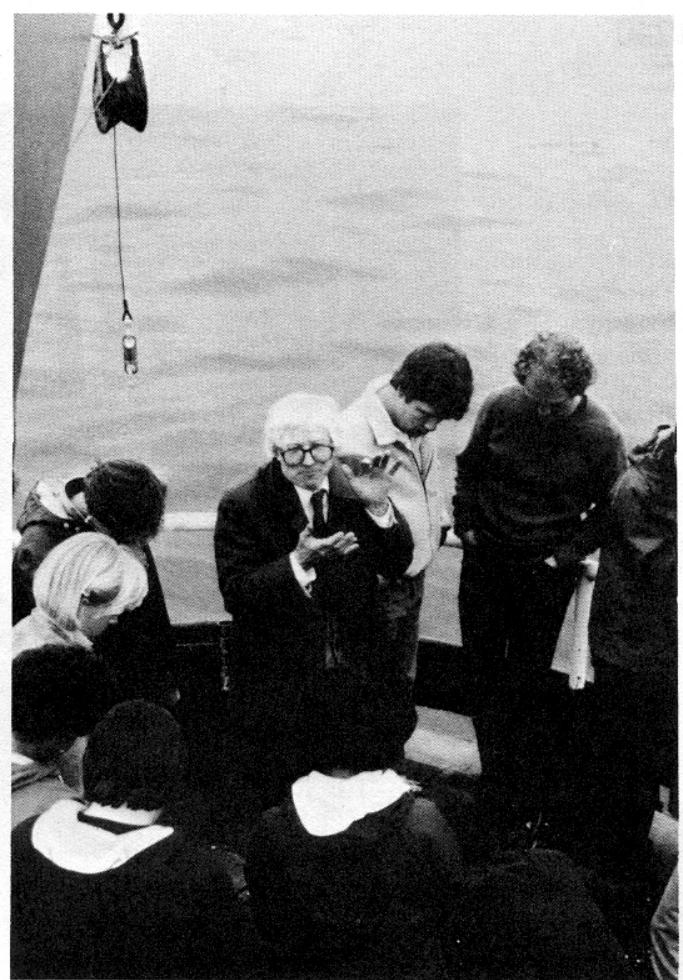

Last class trip, October 1985. (Photo by A. Litt.)

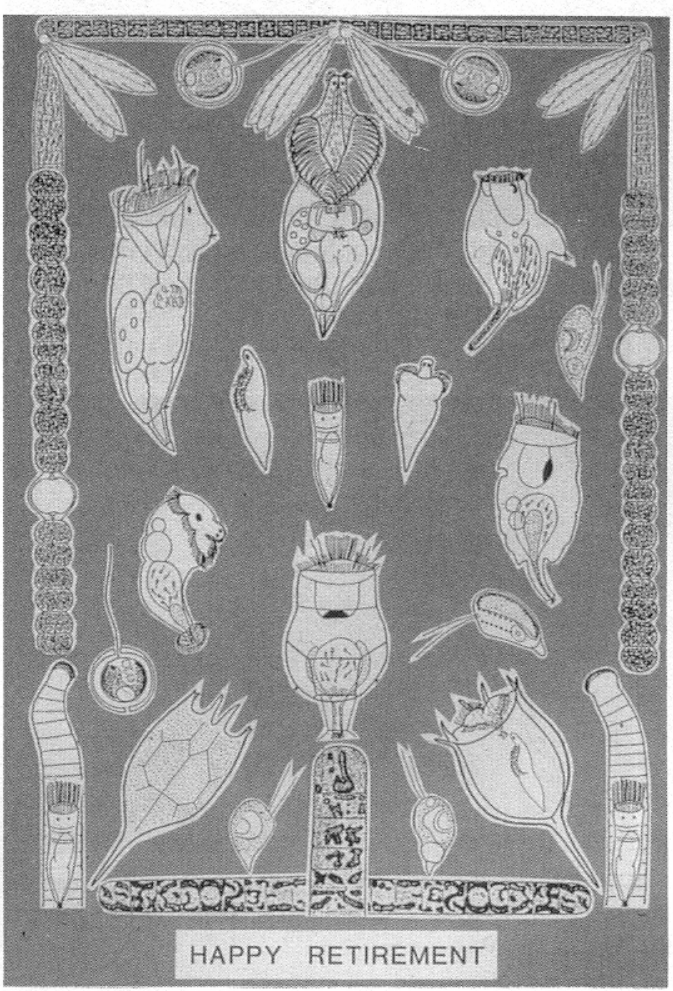

Old friends. (Courtesy J. W. G. Lund.) 


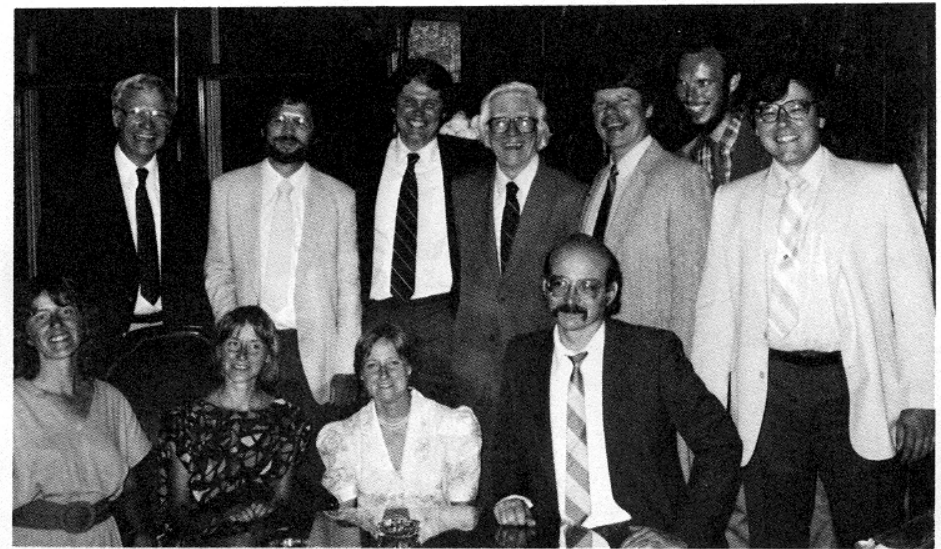

With some of his students, June 1986, in Newport, R.I.

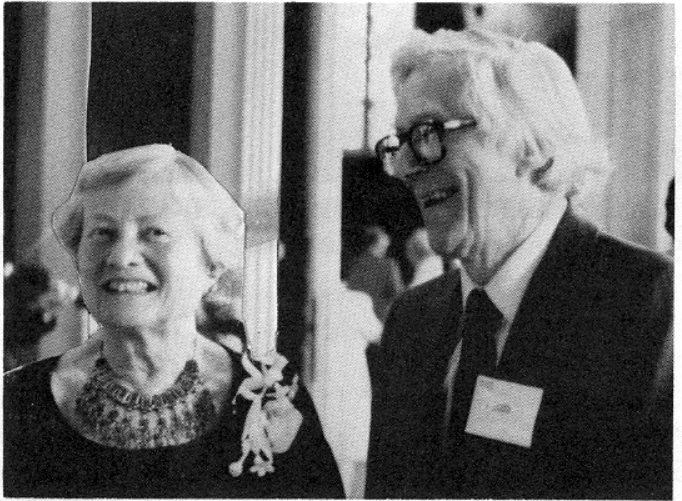

Yvette and Tommy Edmondson, ASLO banquet, Newport, R.I., June 1986. (Photo by Ruth Beeton.)

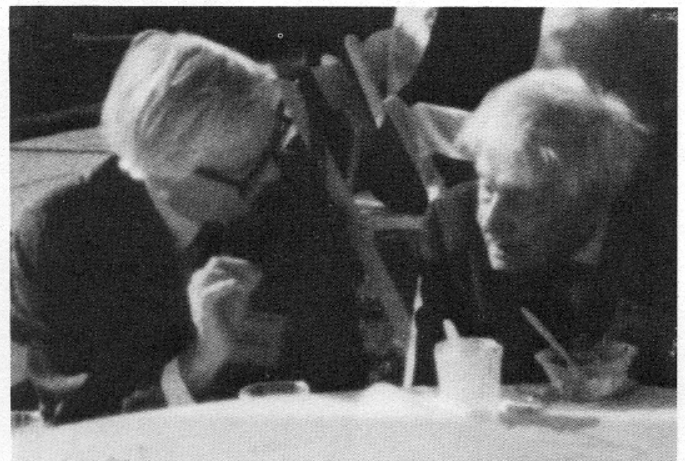

With G. E. Hutchinson, Washington, D.C., meeting of National Academy of Sciences, April 1988. (Photo by Anne Hutchinson.)

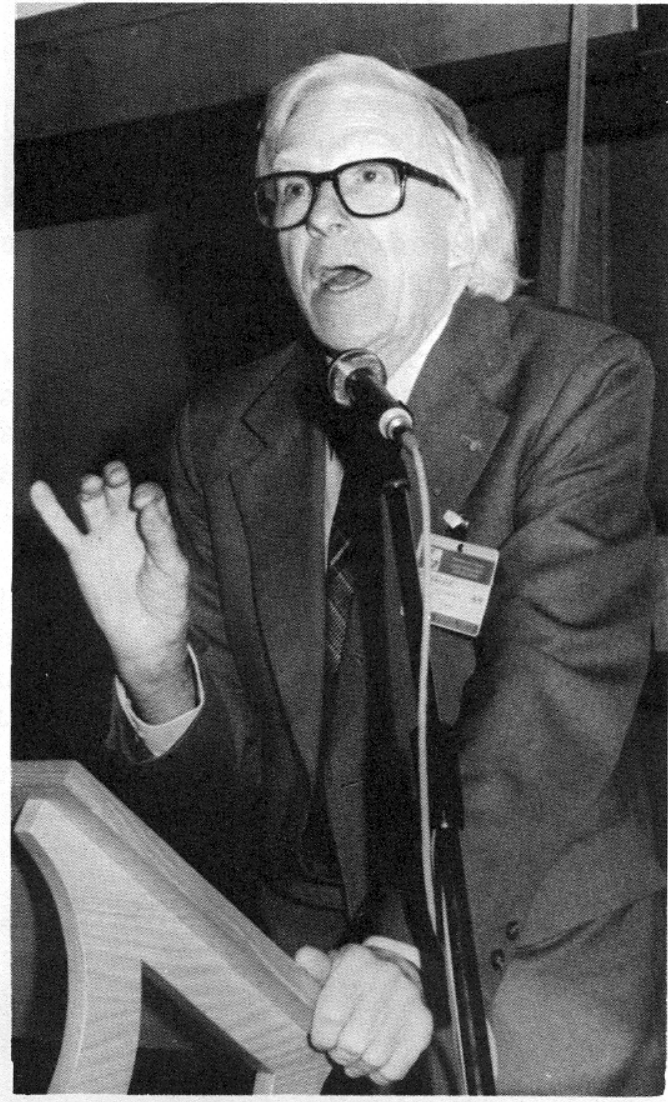

In characteristic pose, speaking at the International Congress on Lake Pollution and Recovery, European Water Pollution Control Association, Rome, April 1985. 